

\section{Introduction - Food security and food waste reduction: a social innovation approach to current social, environmental and political concerns}

\subsection{The intertwining challenges of food security and surplus food management}

Food security has become a salient policy issue at the global level. In low-income countries, the number of people suffering from severe deprivation and lacking access to nutritious food has not diminished at the pace envisaged by international aid and food policy programs. Undernourishment is a reality for about 795 million people in the world according to the Food and Agriculture Organization of the United Nations (hereafter referred to as the FAO) (FAO-IFAD-WFP 2015). At the same time, in high-income countries, global sociodemographic, economic and political changes have led to the impoverishment of larger proportions of their populations, whose needs are at best barely met by ordinary policy measures and services.

Food security, which is defined by the FAO as a situation when "all people, at all times, have physical, social and economic access to sufficient, safe and nutritious food which meets their dietary needs and food preferences for an active and healthy life", is still an issue for part of the European population. The European Federation of Food Banks (FEBA), which includes 265 food banks from 23 European countries, reported that in 2015 it distributed food to 5.7 million EU inhabitants through its partner organisations. More generally, in the same year, so-called "severe material deprivation", which in many cases means diets containing insufficient proteins, impaired the living conditions of $8.2 \%$ of EU citizens (Eurostat's press release 71/2016).

The picture of food insecurity briefly given above is at odds with the available evidence on food waste, a different and (at least in part) independent issue that is acknowledged as a huge worldwide problem. In high-income countries, the amount of edible food wasted on a daily 
basis due to failures at the production, retail and consumption stages, has reached an unbearable level. Bridging food security and food waste questions does not imply any understatement of the food security challenge. The authors of this book share the view that food security is an inherently complex issue which exhibits sizeable differences between high and low-income countries, and demands a coherent and wide set of strategies if it is to be solved at the global and local levels (FAO-IFAD-WFP 2015; Godfray and Charles 2010). However, this book contributes to the academic and policy debates about food poverty by focusing on one particular lever: surplus food policy and management, a strategy that serves the food security goal while reducing food waste. Surplus food is edible food that is produced, manufactured, retailed, or ready to be served, but which for various reasons is not sold to, or consumed by, its intended customers (Garrone et al. 2014a). Preventing surplus food generation at source whenever possible is clearly urgent from the point of view of resource efficiency. However, when prevention is not technically or economically feasible, surplus food management is a high-priority option (Papargyropoulou et al. 2014; Garrone et al. 2016). It means reusing surplus food in primary markets (e.g. through repackaging or remanufacturing), selling it to customers in secondary markets at discounted prices, or redistributing it to food-insecure people in partnership with non-profit organisations. If surplus food is not recovered for human consumption, it then degrades to food waste and requires recycling or disposal.

A quantitative appraisal of food waste helps in motivating our research, because it highlights the unexploited potential of surplus food management, and identifies a gap that should be filled in order to enhance food security. Unfortunately, the available prior studies use different definitions of food waste, and do not always illustrate their sources and estimation methodologies sufficiently thoroughly (Garrone et al., 2014a). Only recently, a multistakeholder commission has attempted to provide governments with a measure protocol 
(http://flwprotocol.org/). The pioneering quantitative study of Gustavsson et al. (2011), which was based on a mass flow model of global food waste and losses, found that food wastage was particularly severe in Europe and North America, with estimates as high as 280-300 kilograms per capita per year. More recently, after collecting data from several European governments and projecting them to the whole region, Stenmark et al. (2016) reported that the EU population generates between 146 and 200 kilograms per capita of food waste every year. However, and aside from questions arising from the absence of data for many countries, this figure cannot inform efforts to manage food surplus for food security purposes, because it also includes the parts of discarded commodities and products that are inherently inedible, an amount that reaches $50 \%$ of food waste figures for some supply chain stages (Stenmark et al., 2016). Estimates focusing purely on the edible parts of food waste have returned lower figures, e.g. about 84 kilograms per capita for Italy (Garrone et al. 2015; see Garrone et al. 2014b for further studies). Despite the methodological problems that still affect food waste estimates, the incongruity between these data and food security statistics is a hint that an integrated approach to these two issues could be of significant value, at least in high-income countries.

\subsection{Food recovery as a social innovation}

Actors from the state, the economy, and the civil society spheres have taken multifaceted action to address the policy and ethical dilemmas related to securing access to nutritious food for all persons, while also avoiding food waste. Among the various options public and private actors have in tackling the issues related to food security is the collection and redistribution of food surplus. Initiatives geared towards the recovery of unsold but still edible food for redistribution to those in need are to be considered forms of social innovation, given that they serve the purpose of meeting unmet social needs while enhancing social assets and capabilities, in line with the definition of social innovation (Sinclair and Baglioni 2014, p. 
471). However, they should also be considered socially innovative because they emanate from unusual patterns of interaction and collaboration within a constellation of actors whose interests may sometimes appear divergent. Food business industry operators, for example, prioritise profit maximisation and economic efficiency, while non-profit organisations or charities focus on their impact on the individuals and communities benefiting from their services. Public actors, such as local or national governments, on the other hand, have to pursue the general interest, although they also need to mediate between competing demands and expectations. The innovations we discuss throughout this book involve social actors who have established long term partnerships based on a mixture of mutual interpersonal trust, professional rigour, and organisational capacity, allowing them to improve life conditions in a given community. Further, they have generally done so while also maintaining their distinctiveness, including their specific priority goals. As we discuss later in the book, such innovations have occurred in similar ways in all four countries analysed here: France, Germany, Italy and Spain. Despite remarkable salient socio-economic and political differences, innovations in food surplus recovery have followed a 'contamination' path in moving from one community to the next, from one country to another, in a reciprocal way, in an endless motion of policy and action learning mechanisms. This book provides an overview of the 'mutual learning mechanisms' we call social innovations.

\subsection{The "Foodsaving" research}

Although surplus food recovery cannot be considered the sole and sufficient means by which to reach a situation of food security for all, it remains a significant area of intervention for policy makers to simultaneously reduce both food poverty and food losses. Indeed, several countries are working in this direction ${ }^{1}$, given that regulations encouraging behavioural

\footnotetext{
${ }^{1}$ In 2016, for instance, the French Parliament passed a new law which made surplus food donation a legal obligation for large food retailers. In 2016, the Italian Parliament passed a new law making food donations easier for companies in the food supply chain.
} 
changes in both citizens and business are pivotal to the realisation of more sustainable food systems, both at global and local levels (Parfitt, 2010).

Both civil society actors (i.e. voluntary organisations, social enterprises, social cooperatives and all various forms of bottom-up movements) and business sector organisations have pivotal roles to play in the recovery, management and redistribution of surplus food. However, relatively little is known about the contribution of non-profit organisations (NPOs) and the strategic and operational changes occurring in business enterprises. In other words, the social innovation behind the partnerships forged between NPOs and the business sector in this field have scarcely been studied to date; this book therefore provides the first comprehensive analysis of these innovative partnerships, and of the positive impact which they may have on food security issues.

The book originates from an international comparative research study entitled "Foodsaving: social innovation applied to food surfeits recovery", which was funded by the Cariplo Foundation, the Lombardy Region and the EU, and developed through the partnership of three Milan-based universities: Bocconi University, Università Cattolica del Sacro Cuore ALTIS, and the Politecnico di Milano University. The research lasted from September 2013 until September 2015, and aimed to identify the best practices in terms of governance models, processes and services implemented in the surplus food recovery chain by the business sector and non-profit organisations. Innovative experiences in recovering surplus food were studied across five European macro-regions: Lombardy (Italy), Baden-Württemberg (Germany), Catalunya and Madrid (Spain), and Rhöne-Alpes (France). These regions were chosen because they are among the most affluent in Europe, but at the same time, they also contain areas of severe deprivation, including food poverty, that have generated the pioneering socially innovative policy answers discussed in this book. 
The three key disciplines of the research are the management of non-profit and social enterprise organisations, operations and supply chain management, and policy analysis. Such a multidisciplinary approach has allowed the investigation of surplus food recovery practices from different viewpoints (public policy and governance, business sector and the non-profit sector), which are brought together in the book.

A multiple case study methodology based on qualitative data collection methods was used to conduct the present research (Yin, 2009): 65 case studies were selected through the use of both purposive and snowball sampling (Bryman, 2001). These case studies investigated both the business side and the non-profit side of the topic; the business case studies included producers, manufacturers, retailers and food service companies, while the non-profit case studies included social cooperatives, voluntary organisations and social enterprises. The case studies were distributed as follows among the four countries: 42 in Italy (22 companies and 20 NPOs), 7 in France (5 business and 2 NPOs), 12 in Spain (5 business and 7 NPOs) and 5 in Germany (all NPOs). Unexplored settings with a number of highly knowledgeable informants were chosen to build theory from the case studies. Semi-structured face-to-face interviews and observation moments were used to explore all the case studies, and the interviews were conducted with supply chain and logistics managers of food manufacturing and retail companies as well as with representatives of non-profit organisations. The interviews were recorded where possible, and transcribed to allow cross-coding and thematic analysis (Saldana, 2009), taking into account data saturation to ensure research validity.

\subsection{Book structure}

The book is divided into three parts, each focusing on one main dimension of the analysis of the organisations and policies involved in surplus food recovery. Part I deals with food recovery policies in Europe. In this part, Chapters 1 and 2 analyse the policies which, at both the EU and Member States levels, support or obstruct surplus food recovery, with specific 
discussions of the relevant regulations and legislation across European countries and, at the EU level, the EU-wide attempts to encourage a behavioural change at individual and business levels in order to reduce food waste and to improve general consumption patterns.

Part II focuses on the best practices among the food industry operators which donate their surplus food to NPOs. Chapter 3 builds a conceptual framework to identify and understand the key-organisational features conducive to food companies donating their surplus food for redistribution to those in need. Developed through four exploratory case-study analyses, this theoretical framework points to four key-factors: measurement procedures, the organisation of the process, coordination among functions, and the donation process configuration. In chapter 4, this theoretical framework is tested against 23 case studies across three countries (France, Italy and Spain). The chapter reveals that food business operators with greater redistribution intensity manage surplus food through the use of critical indicators, structured processes, and partnerships with non-profit organisations. Moreover, an in-depth analysis of two cases, one of which is a manufacturer and the other a retailer, is used to illustrate the practical relevance of the model.

Part III focuses on non-profit organisations, and in this section of the book, the authors present different models to analyse the collection, management and distribution of food surplus across four countries (France, Germany, Italy and Spain). Chapter 5 develops a conceptual framework which can be used to study the food recovery, management and redistribution systems in those four countries from the perspective of food charities and nonprofit organisations while focusing on the constraints and enablers of NPOs' capacities to manage surplus food recovery and redistribution. Three interrelated dimensions are identified as influencing the process of recovery and distribution of food surplus: relational capital, structural capital, and human capital. Chapter 6 uses 34 case studies of non-profit actions across the four countries to discuss best practices with regard to surplus food recovery and 
redistribution, using the different dimensions of the conceptual model for reference. An indepth description of the collection, management and redistribution processes is highlighted for the selected organisations, exploring their strengths in relation to the dimensions of the model.

Finally, chapter 7 connects together all the different actors in food chain recovery, in order to discuss an integrated, multi-actor solution to tackle food recovery problems, before identifying the conclusions and limitations of this work, and suggesting some directions for further research. 